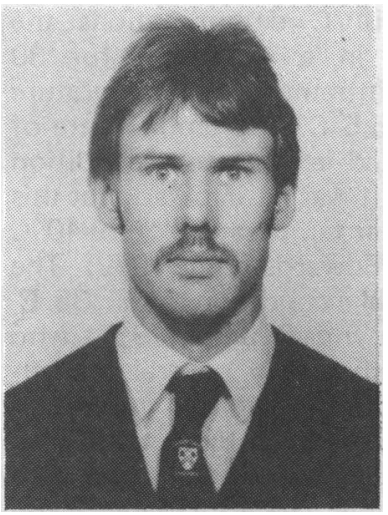

T. J. Barter

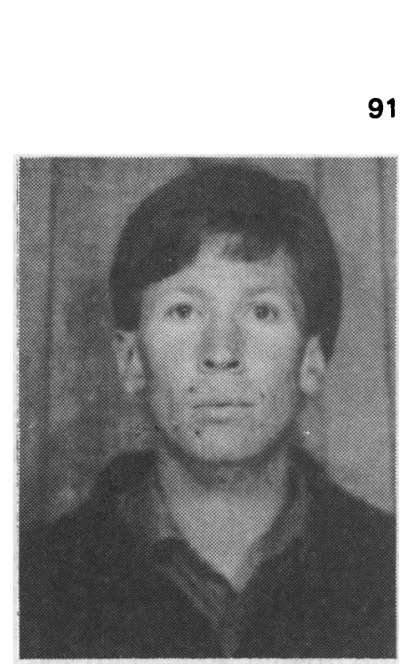

P. C. Freer

\title{
EFFECT OF TEMPERATURE ON HANDGRIP HOLDING TIME
}

\author{
T. J. BARTER, MSc and P. C. FREER, BEd
}

Madeley School of Physical Education, North Staffordshire Polytechnic, Madeley Site, Madeley, Crewe, CW3 9HY

\begin{abstract}
\end{abstract}
The effect of intramuscular temperature upon the holding time of $70 \% \mathrm{MVC}$ handgrip contraction was studied in $12 \stackrel{3}{\mathrm{~s}}$ college-age men. The intramuscular temperature was regulated by $\mathbf{3 0}$ minutes immersion of the forearm and hand in a

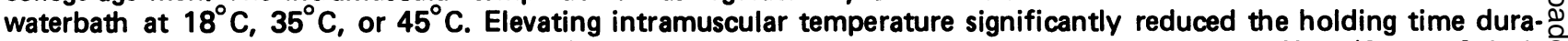
tion, $(25.7 \pm 6.2$ vis $38.3 \pm 8.1, P<0.01)$, while reducing the temperature had no significant effect $(37.5 \pm 9.4$ vis $\stackrel{\mathbb{Q}}{\mathscr{Q}}$ $38.3 \pm 8.1$, N.S.).

Key words: Handgrip holding time, Elevated and reduced temperature.

\section{INTRODUCTION}

In man, the resting intramuscular temperature has been variously reported as $33^{\circ} \mathrm{C}$ (Binkhorst et al, 1977), $35^{\circ} \mathrm{C}$ (Saltin et al, 1968), $35.1^{\circ} \mathrm{C}$ (Edwards et al, 1972) and $38.5^{\circ} \mathrm{C}$ (Bergh and Ekblom, 1979). Some of this variability may be due to sample size, different muscle groups, variation between different sites in the same muscle (Edwards et al, 1972), depth of recording (Petrofsky and Lind, 1975; Saltin et al, 1968) or measuring technique. The temperature of limb muscles can vary quite widely and in everyday life it is not inconceivable for intramuscular and skin temperature to vary by $10^{\circ} \mathrm{C}$, inherent factors such as body fat (Petrofsky and Lind, 1975) and arm girth (Clarke et al, 1958) affect

\section{Present address:}

Geography and Recreation Studies Department, North Staffordshire Polytechnic,

Leek Road,

Stoke-on-Trent,

ST4 2DF temperature distributions. In experimental situations it $\dot{\overrightarrow{0}}$ has been easy to raise or lower intramuscular tempera- 3 ture by immersion in water (Binkhorst et al, 1977; Clarke et al, 1958; Edwards et al, 1972).

Elevation of intramuscular temperature by a few degrees centigrade has been shown to reduce handgrip endurance (Clarke et al, 1958), forearm flexion isometric endurance (Barter et al, 1982) and knee exten- $\sigma$ sion isometric endurance (Edwards et al, 1972) signif- $N$ icantly. While reducing intramuscular temperature tends $\underset{\mathrm{W}}{\mathrm{\omega}}$ to increase holding time duration (Clarke et al, 1958). 웅 The percentage maximum voluntary contractions (MVC) used by these studies varied from 33\% MVC (Clarke et al, 1958) to $80 \%$ MVC (Barter et al, 1982). ? Humpreys and Lind (1963) reported that percentage 0 MVC's of $70 \%$ or greater were probably required to cause occlusion of blood flow through forearm muscles. By comparison, in leg muscles occlusion may occur at $\mathbb{8}$ forces greater than 20\% MVC (Shepherd et al, 1981). Thus in most of these studies cited above blood flow 
would still have been a factor in the isometric endurance times. Another factor relating to holding time duration would be the muscle fibre type recruitment pattern. Most muscles in man are comprised of a variable mixture of fast and slow twitch units (Dobowitz and Brooke, 1974). For weak isometric contractions the slow twitch motor units are considered to be recruited first through to the fast twitch motor units (Milner-Brown and Stein, 1975). At progressively higher tensions the fast twitch motor units tend to dominate, with their anaerobic enzyme profile tending to lead to a more rapid development of fatigue (Gollnick, 1982). Thus, this study sought to investigate the effects of cold $\left(18^{\circ} \mathrm{C}\right)$, neutral $\left(35^{\circ} \mathrm{C}\right)$ and hot $\left(45^{\circ} \mathrm{C}\right)$ waterbath temperatures on handgrip holding time at $70 \% \mathrm{MVC}$.

\section{METHODS}

Twelve physically active men whose ages ranged between 19-25 years volunteered to participate in the study and each signed an informal consent letter. The twelve were randomly selected from a year group of students. Subjects received a familiarisation session followed by three test sessions, each separated by at least twentyfour hours.

The three treatment conditions consisted of an evaluation of base-line handgrip maximum voluntary contraction (MVC), followed by a single holding time trial at $70 \%$ base-line MVC under three temperature conditions. The temperature conditions were controlled by immersion of the forearm and hand in a waterbath at $18^{\circ} \mathrm{C}$, or $45^{\circ} \mathrm{C}$ for 30 minutes.

Base-line MVC measures were determined at the beginning of each test session and the $70 \%$ MVC value calculated. The pattern of development of MVC conformed to that suggested by Caldwell et al (1974). After a build-up phase of no more than 2 seconds, the subjects were required to maintain a steady maximal exertion for at least 3 seconds. Four base-line MVC determinations were assessed for each session. These comprised 2 MVC's with 1 minute rest between trials, 5 minutes passive rest, then another 2 MVC trials with 1 minute between trials. The MVC determinations were conducted with the subject seated at a bench with his dominant arm securely strapped to reduce extraneous movement. Two leather cuffs were used to reduce arm movement, one secured in the region of the elbow joint and the other at the wrist. Trunk movement was reduced by the torso being secured between the bench top and a high-backed chair. A Jamar adjustable handgrip dynamometer was held in the dominant hand and upon instruction from the investigator the MVC performed. The handgrip span of the dynamometer was set at 6 centimetres as suggested by Petrofsky et al (1980). The calibration of the handgrip dynamometer was checked before each test session in accordance with the manufacturer's instructions (Asimow Engineering Co.).
Following the base-line MVC determinations the subject placed his forearm in a waterbath for 30 minutes. Reports of resting intramuscular temperature vary but appear to average $35.5^{\circ} \mathrm{C}$. The temperature of the waterbath for the elevated temperature condition was maintained at $45^{\circ} \mathrm{C}$, and it was anticipated that this would result in an intramuscular temperature of $39-40^{\circ} \mathrm{C}$ after 30 minutes immersion (Edwards et al, 1972). The temperature for the neutral condition was $35^{\circ} \mathrm{C}$, following the work of Craig and Dvorak (1967) who found $35^{\circ} \mathrm{C}$ to be the most thermally neutral temperature. The cold condition was $\mathbf{3 0}$ minutes immersion at $18^{\circ} \mathrm{C}$. Clarke et al $(1958)$ found $15^{\circ} \mathrm{C}$ to be the threshold for subjects to begin experiencing pain, so $18^{\circ} \mathrm{C}$ was adopted for this study. The anticipated intramuscular temperature under the cold condition, following 30 minutes immersion, was about $26^{\circ} \mathrm{C}$ (Clarke et al, 1958).

Following the $\mathbf{3 0}$ minute immersion a single $\mathbf{7 0 \%}$ MVC handgrip holding time to volitional fatigue was performed. The hand was removed from the bath, dried and secured to the bench. The Jamar handgrip dynamometer was taken in the dominant hand and the $70 \%$ force level attained within 5 seconds. The duration of the holding time was taken to be from the time the subject achieved the required value until the point when the subject was unable to maintain the $70 \%$ MVC value for three consecutive seconds. The same degree of verbal motivation was given to each subject.

The order of presentation of treatment conditions was balanced to minimise an order effect and subjects were given no information with regard to expected or previous results.

\section{RESULTS}

The height, weight and forearm girth of the subjects was found to be $178.2 \pm 4.3 \mathrm{~cm}, 70.4 \pm 5.5 \mathrm{~kg}$, and 27.3 $\pm 1.7 \mathrm{~cm}$ respectively.

The base-line handgrip MVC measurement means, standard deviations and ranges for the three test days are given in Table I.

An ANOVA with repeated measures was performed on the base-line MVC means for the subjects over the three test days. The observed $F$ ratio failed to reach the value required for significance $\left(F_{2,22}=0.16, P>0.05\right)$. This suggests that there was no significant difference in strength measures over the test days and that base-line handgrip strength measures were reliably assessed.

The $70 \%$ handgrip holding times under the three treatment conditions are given in Table II. A repeated measures ANOVA of the holding times over the treatment conditions resulted in a significant $F$ ratio $\left(F_{2,22}=\right.$ 21.04, $P<0.01$ ). The administration of a Tukey Test 
TABLE I

Base-line MVC's over days

$\begin{array}{lccc} & \text { Mean }(\mathrm{kg}) & \text { Standard Deviation } & \text { Range } \\ \text { Day 1 } & 43.2 & 5.1 & 35.9-55.2 \\ \text { Day 2 } & 45.6 & 5.7 & 35.9-59.8 \\ \text { Day 3 } & 43.0 & 5.2 & 35.0-56.0\end{array}$

TABLE II

Handgrip holding times at $70 \%$ MVC

$\begin{array}{lccc} & \text { Mean (seconds) } & \text { Standard Deviation } & \text { Range } \\ \begin{array}{l}18^{\circ} \mathrm{C} \text { Cold } \\ \text { Condition }\end{array} & 37.5 & 9.4 & 22.0-59.0 \\ \begin{array}{l}35^{\circ} \mathrm{C} \text { Neutral } \\ \text { Condition }\end{array} & 38.3 & 8.1 & 25.0-53.0 \\ \begin{array}{l}45^{\circ} \mathrm{C} \text { Elevated } \\ \text { Condition }\end{array} & 25.7 & 6.2 & 19.0-40.0\end{array}$

indicated that there was no significant difference between the cold and neutral temperature conditions, while the elevated temperature condition was significantly different from the other two.

Pearson product-moment correlations between baseline handgrip strength and body weight, height and forearm girth were all non-significant, as were the correlations between holding time and the same anthropometric variables.

\section{DISCUSSION}

It has long been known that body weight and maximum strength tend to be related. Indeed stronger relationships have been reported between body weight and maximum isometric strength, than between fibre composition and forearm flexion isometric strength (Barter et al, 1982; Clarkson et al, 1982).

However, this study failed to find a significant correlation between maximum handgrip strength and body weight ( $r=0.42, N . S$.). It may be suggested that since the muscles involved in the contraction are small, the relationship to body weight may not exist, whereas, with forearm flexion the muscles involved are larger and so the relationship may apply. Close examination of individual results show that one subject (a hockey player) had a relatively low body weight but the highest handgrip MVC. In fact the variation in the results as a whole is low (refer to Table I) and this probably contributed to the low correlation.

The duration of the $70 \%$ MVC holding time under neutral conditions was $38.3 \pm 8.1$ seconds, this is consistent with holding times reported from other studies. For example, $80 \%$ MVC for forearm flexion has been reported as $32.2 \pm 9.8$ seconds (Barter et al, 1982),
$40 \%$ MVC handgrip holding time was $47 \pm 12$ secondsco (Duncan et al, 1981) and 70\% MVC handgrip holding time at a water bath temperature of $40^{\circ} \mathrm{C}$ was found to average $47 \pm 3$ seconds (Petrofsky and Lind, 1980). The actual limit of an endurance contraction may be $\stackrel{5}{?}$ attributable to a number of factors; reduction in the? muscle's energy stores, build-up of waste products, failure of neuromuscular function, or psychological $\frac{\rho}{5}$ factors. With blood flow restricted via the constricting $\propto$ action of intramuscular pressure, the muscles are working predominantly via anaerobic energy sourcesand waste products must remain in the vicinity of the muscle. The work of Karlsson et al (1975) on isometric $\overrightarrow{\vec{\omega}}$ contractions of the quadriceps femoris muscle found $\stackrel{5}{\circ}$ that following contractions at 30,50 and $80 \%$ MVC the creatine phosphate stores in the muscle were almost? depleted. Indeed a certain degree of creatine phosphate $\vec{\infty}$ resynthesis may have occurred between muscle sampling i $^{\circ}$

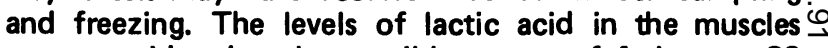
were considered to be possible causes of fatigue at 30 을 and $\mathbf{5 0 \%}$ MVC, but not at 20 and $80 \%$ MVC (Karlsson et al, 1975). At 20\% MVC the blood flow to the quadri- $\subseteq$ ceps femoris muscle is unlikely to be occluded and so at this low exercise intensity the muscle metabolism is $\vec{D}$ almost entirely aerobic, thus, not producing high levels $\biguplus_{\infty}$ of lactic acid. Whereas, at $80 \%$ MVC blood flow is. occluded thus, placing an almost total reliance upon anaerobic metabolism. Since the exercise intensity is almost maximal and fatigue occurs rapidly there is insufficient time for lactic acid levels to reach a peak. The accumulation of lactic acid was high $(27.1$ mmole $\stackrel{\perp}{\perp}$ $\mathrm{kg}^{-1}$ wet $\mathrm{wt}$ muscle) and comparable with levels found $\overrightarrow{\vec{F}}$ during fatigue induced by rhythmic exercise at $30 \% \frac{\mathrm{O}}{3}$ MVC (Karlsson, 1971). The $\mathrm{pH}$ balance of the cell is crucial for the optimum functioning of the enzyme systems. Alterations in the cytoplasmic $\mathrm{pH}$ may change the chemical bond relationships in the enzyme molecule, thereby changing the quaternary structure of the protein possibly, causing a loss of function (Karp, 1979). An important rate limiting enzyme in the energy release pathway, phosphofructokinase, is known to be sensitive $\frac{\circ}{3}$ to the hydrogen ion concentration (Edington and Edgerton, 1976). Nakamara and Schwartz (1972) have reported that the concentration of hydrogen ions is $\frac{\vec{O}}{0}$ an important factor in inhibiting the contraction process, via calcium release and uptake by the sarco- $N$ plasmic reticulum. The hydrogen ions also have a more $N$ direct influence via the enzyme myosin adenosine $N$ triphosphatase (ATPase) (Nakamara and Schwartz, $\sigma$ 1972), in that, the change in $\mathrm{pH}$ would affect the chemical structure of the molecule thereby reducing its efficiency as an enzyme.

The finding that elevating the intramuscular temper- $\frac{0}{0}$ ature significantly reduced the duration of the holding $\stackrel{\odot}{\rightarrow}$ time was in accord with previous results (Barter et al, $\stackrel{\square}{\square}$ 1982; Clarke et al, 1958; Edwards et al, 1972; Petrofsky and Lind, 1980). This study did not find a 8 
significant difference between $70 \%$ holding times at waterbath temperatures of $18^{\circ} \mathrm{C}$ and $35^{\circ} \mathrm{C}$. Petrofsky and Lind (1980) found that handgrip endurance of $70 \%$ MVC at a waterbath temperature of $20^{\circ} \mathrm{C}$ resulted in peak holding times, similarly Clarke et al (1958) found a waterbath temperature of $18^{\circ} \mathrm{C}$ resulted in peak isometric endurance of a $33 \%$ MVC handgrip contraction. The results of our study did not show that the greatest endurance time at $70 \%$ MVC was achieved at a lower temperature $\left(18^{\circ} \mathrm{C}\right)$. This lack of agreement with the results of Clarke et al (1958) and Petrofsky and Lind (1980), who both found peak handgrip endurance to occur at reduced temperatures, might have occured as a result of different experimental procedures. One important difference was that for both of the other experiments the waterbath in which the arm was immersed was stirred vigorously, thus increasing the cooling effect. Also, the actual handgrip contraction in this experiment was performed out of the water, whereas the contraction was performed in the water with the experiments of Clarke et al (1958) and Petrofsky and Lind (1980). The resultant effect of these two differences would be that the intramuscular temperature of the subjects in this experiment might not be as low as those produced in comparable experiments.

The cause of the reduction in holding time with elevation of intramuscular temperature is unclear. Chemical reactions proceed at a faster rate under heated conditions which may lead to a faster depletion of energy stores. In addition, the temperature may affect the stability of the myosin-actin crossbridges and more energy may be required to maintain tension. Similarly, the membrane integrity of the muscle and nerve cells may be reduced, disrupting ion balances, causing some high energy phosphate stores to be used to maintain the equilibrium and integrity.
A factor which may contribute to the reduction in holding time under elevated temperature might be a redistribution in blood. Since the blood flow through the arm was occluded at $70 \%$ MVC the circulatory system would respond by a vasodilation of the subcutaneous blood vessels, leading to a redistribution of blood in favour of the subcutaneous areas at the expense of the muscles. This would lead to a greater dependence upon anaerobic energy release causing a lactic acid buildup in the working muscle and a decrease in holding time (McArdle et al, 1981).

It has been shown that in human muscle, motor units with a low discharge frequency are recruited before motor units with a higher discharge frequency (Hannerz, 1974). Also it has been suggested that slow twitch fibres are activated at mild voluntary contractions, whereas fast twitch fibres are activated during more vigorous contractions (Gollnick et al, 1973; Warmolts and Engel, 1972). Barter et al (1982) suggested that heating a muscle may serve to amplify the heat production in fast twitch fibres, which was shown by Bolstad and Ersland (1978) to be some six times greater than the heat produced by slow twitch fibres during maximal energy turnover. Thus the amplified heat production in recruited fast twitch fibres may reduce isometric endurance.

The results of this study have shown that isometric endurance at $70 \%$ MVC of handgrip strength was significantly reduced following immersion of the forearm in hot water $\left(45^{\circ} \mathrm{C}\right)$. This reduction in isometric endurance capacity was probably the result of the influence of elevated intramuscular temperature on the contractile processes. Also, that body weight was not significantly related to handgrip strength.

\section{REFERENCES}

Barter, T. J., Clarkson, P. M. and Melchionda, A., 1982 "The relationship of forearm flexion isometric strength, endurance and fibre composition, and the effect of heating". Int.J.Sports Medicine 3 (3): 145-148.

Bergh, U. and Ekblom, B., 1979 "Influence of muscle temperature on maximal muscle strength and power output in human skeletal muscle". Acta Physiol.Scand. 107: 33-37.

Binkhorst, R. A., Hoofd, L. and Vissers, A. C. A., 1977 "Temperature and force-velocity relationships of human muscles". J.Appl.Physiol. 42: 471-485.

Bolstad, G. and Ersland, A., 1978 "Energy metabolism in different human skeletal muscles during voluntary isometric contractions". Eur.J.Appl.Physiol. 38: 171-179.

Caldwell, L., Chaffin, D. B., Dukes-Dobbs, F., Kroemer, N., Laubach, L. L., Snook, S. H. and Wasserman, D. E., 1974

"A proposed standard procedure for static muscle strength testing". Am. Indust. Hygiene Assn.J. 35: 201-206.

Clarke, R. S. J., Hellon, R. F. and Lind, A. R., 1958 "The duration of sustained contractions of the human forearm at different temperatures". J.Physiol.(London) 143: 454-473. 
Clarkson, P. M., Kroll, W. and Melchionda, A., 1982 "Isokinetic strength, endurance, and fibre type composition iß elite American paddlers". Eur.J.Appl.Physiol. 48 (1): 67-76.

Craig, A. and Dvorak, M., 1967 "Thermal regulation during water immersion". J.Appl.Physiol. 23: 423-425.

Dubowitz, V. and Brooke, M., 1974. Muscle Biopsy, a Modern Approach. W. B. Saunders, Philadelphia.

Duncan, G., Johnson, R. H. and Lambie, D. G., 1981 "Role of sensory nerves in the cardiovascular and respiratorys changes with isometric forearm exercise in man". Clin.Sci. 60: 145-155.

Edington, D. W. and Edgerton, V. R., 1976. The Biology of Physical Activity. Houghton Mifflin Co., Boston.

Edwards, R. H. T., Harris, R. C., Hultman, E., Kaijser, L., Voh, D. and Nordesjö, L. O., 1972 “Effects of temperaturë on muscle energy metabolism and endurance during successive isometric contractions sustained to fatigue of the quadrig ceps muscle in man". J.Physiol.(London) 220: 335-352.

Gollnick, P. D., Karlsson, J. and Saltin, B., 1973 “Glycogen depletion in human skeletal muscle fibres during isometrigo contraction". Physiologist 16: 325.

Gollnick, P. D., 1982 "Relationship of strength and endurance with skeletal muscle structure and metabolic potential" Int.J.Sports Med. 3: 26-32. Hannerz, J., 1974 “Discharge properties of motor units in relation to recruitment order in voluntary contraction'公
Acta Physiol.Scand. 91: 374-384.

Humpreys, P. W. and Lind, A. R., 1963 "The blood flow through active and inactive muscles in the forearm duringe sustained handgrip contractions". J.Physiol.(London) 166: 120-135.

Karlsson, J., Funderbusk, C. F., Essen, B. and Lind, A. R., 1975 "Constituents of human muscle isometric fatigue" J.Appl.Physiol. 38: 208-211.

Karlsson, J., 1971 "Lactate and phosphagen concentrations in working muscles of man with special reference to oxygeî尺 deficit at the onset of work". Acta Physiol.Scand.Suppl. 358.

Karp, G., 1979. Cell Physiology. McGraw-Hill, New York.

McArdle, W. D., Katch, F. I. and Katch, V. L., 1981. Exercise Physiology: Energy, Nutrition and Human Performance. Lea and Febiger, Philadelphia.

Milner-Brown, H. S. and Stein, R. B., 1975 "The relation between the surface electromyogram and muscular force" J.Physiol. (London) 246: 549-569.

Nakamara, Y. and Schwartz, S., 1972 "The influence of hydrogen ion concentration on calcium binding and release by skeletal muscle sarcoplasmic reticulum". J.General Physiol. 59: 22-32.

Petrofsky, S. J. and Lind, A. R., 1975 "The relationship of body fat content to deep muscle temperature and isometris endurance in man". Clin.Sci.Mol.Med. 48: 405-412.

Petrofsky, S. J., Williams, C., Kamen, G. and Lind, A. R., 1981 “The effect of handgrip span on isometric exercise pepo formance". Ergonomics 23 (12): 1129-1135.

Petrofsky, S. J. and Lind, A. R., 1980 "The influence of temperature on the amplitude and frequency components o\$ the EMG during brief and sustained isometric contractions". Eur.J.Appl.Physiol. 44: 189-200.

Saltin, B., Gagge, A. P. and Stolwijk, J. A. J., 1968 "Muscle temperatures during submaximal exercise in man". J.App涼 Physiol. 25: 779-788.

Shepherd, J. T., Blomqvist, C. B., Lind, A. R., Mitchell, J. H. and Saltin, B., 1981 "Static isometric exercise. Retro spection and introspection". Circ. Res. 48: I-179- I-188.

Warmolts, J. R. and Engel, W. K., 1972 “Open-biopsy electromyography”. Arch.Neurol.(Chic.) 27: 512-517. 